\title{
Use of Pluronic P103 Triblock Copolymer as Structural Agent during Synthesis of Hybrid Silver Nanoparticles
}

\author{
Nancy Tepale $\mathbb{D}^{1}{ }^{1}$ Víctor V. A. Fernández-Escamilla, ${ }^{2}$ Eric Flores-Aquino, ${ }^{3}$ \\ Manuel Sánchez-Cantú $\mathbb{D}^{\mathbb{D}},{ }^{1}$ Adan Luna-Flores $\mathbb{D}^{1},{ }^{1}$ and Valeria J. González-Coronel $\mathbb{B D}^{1}$ \\ ${ }^{1}$ Facultad de Ingeniería Química, Benemérita Universidad Autónoma de Puebla, Puebla 72570, Mexico \\ ${ }^{2}$ Departamento de Ciencias Tecnológicas, Universidad de Guadalajara, Ocotlán, Jalisco 47820, Mexico \\ ${ }^{3}$ Departamento de Nanocatálisis, Centro de Nanociencias y Nanotecnología, Universidad Nacional Autónoma de México, Ensenada, \\ Baja California 22860, Mexico
}

Correspondence should be addressed to Nancy Tepale; nancy.tepale@correo.buap.mx

Received 28 September 2019; Accepted 3 December 2019; Published 20 December 2019

Academic Editor: Thathan Premkumar

Copyright ( 2019 Nancy Tepale et al. This is an open access article distributed under the Creative Commons Attribution License, which permits unrestricted use, distribution, and reproduction in any medium, provided the original work is properly cited.

Dilute aqueous solutions of triblock copolymer Pluronic P103 were used to synthesize silver nanoparticles (Ag-NPs) by chemical reduction of silver nitrate $\left(\mathrm{AgNO}_{3}\right)$ with sodium borohydride $\left(\mathrm{NaBH}_{4}\right)$. This copolymer was used as a structural agent since monomers act as a stabilizer and micelles act as nanoreactors for nucleation and growth of Ag-NPs. The growth of the nanoparticles (NPs) was monitored by UV-visible spectroscopy on the basis of measuring surface plasmon resonance absorption over a temperature range of 25 to $70^{\circ} \mathrm{C}$. Shape and size of hybrid silver/P103 nanomaterials were tuned by varying the micellar structure of Pluronic P103 using a simple synthesis procedure. Dynamic Light Scattering (DLS) and Transmission Electron Microscopy (TEM) were used to study the size and shape of the hybrid nanomaterials. It was observed that Ag-NPs synthesized without Pluronic P103 at $25^{\circ} \mathrm{C}$ exhibited a great variety of sizes. However, when Pluronic P103 was used below its critical micellar concentration (CMC), spherical-shaped Ag-NPs with uniform size were formed, suggesting that the copolymer had a stabilizing effect. On the other hand, when Ag-NPs were prepared with Pluronic P103 above the CMC, NPs with similar sizes as the micelles were detected, suggesting that the copolymer functioned as a nanoreactor. Furthermore, as temperature reached $35^{\circ} \mathrm{C}$, oval-shaped micelles were formed and small NPs were incorporated into the crown of the micelles. Independent Ag-NPs were not observed since they used the surface of the micelles as a soft template. Therefore, it was possible to obtain tiny Ag-NPs with homogeneous size.

\section{Introduction}

Metal NPs can perform as smart structures due to certain inherent properties that make them suitable for potential technological uses in the optical [1], medical [2], catalytic $[3,4]$, and electronic [5] fields. These particles are currently highly used in quotidian products $[6,7]$. Optical, electronic, and catalytic properties of these materials are highly dependent on their size, composition, and shape. Sakai and Alexandridis [8] were pioneers synthesizing gold NPs using commercially available polymers (amphiphilic molecules). Poly(ethylene oxide)-poly(propylene oxide)-poly(ethylene oxide) (PEO-PPO-PEO) triblock copolymers or Pluronics were used as reducing, stabilizing, and morphogenic agents in a single-step synthesis of gold NPs. During this process, micellar cores of Pluronics performed as nanosized reaction vessels for metal colloid formation. This method is friendly with the environment since it uses water as a solvent making it cheap at the same time. In water, Pluronics form micelles above the critical micellar temperature (CMT) and the CMC [9]. Moreover, when increasing the temperature high above the CMT, a phase separation occurs at a temperature known as the cloud point temperature (CPT). At this point, micelles dehydrate, achieving a predominantly hydrophobic environment [10].

In a more recent publication, Sakai et al. [11] reported the synthesis of Ag-NPs in aqueous solutions of Pluronics (F88, F127, and F108) in the absence of any additional agents, with 
the disadvantage being the need for high synthesis temperatures (above $100^{\circ} \mathrm{C}$ ). They observed that high concentration of Pluronics enhanced the reduction of $\mathrm{Ag}^{+}$, leading to the formation of Ag-NPs. Formation of spherical, plate-like and rod-like Ag-NPs was observed using TEM analysis [11]. Furthermore, Ag-NPs were synthesized by chemical reduction of silver nitrate $\left(\mathrm{AgNO}_{3}\right)$ employing dopamine as a reducing and sticking agent while Pluronic F127 was used as a stabilizer. Under these conditions, Ag-NPs were uniformly deposited in network-like F127 micelles. The size of individual Ag-NPs was between 5 and $20 \mathrm{~nm}$ with spherical shapes [12]. In addition, Pluronic F127 was used as a capping agent in Ag-NP synthesis with an excess of $\mathrm{NaBH}_{4}$. The copolymer acted as a stabilizer and promoted the agglomeration of individual Ag-NPs while modifying their characteristic plasmon band [13]. On the other hand, different micellar assemblies of block copolymers can act as soft templates since reactions are carried out at the micelle-solution interface on the surface cavities [10]. For instance, small Ag-NPs with a narrow size distribution have been reported when using a triblock copolymer micellar network [14].

Although the synthesis of NPs has been studied extensively and different growth mechanisms have been suggested, real control over this process and in consequence on the properties of the particles still remains a challenge. Therefore, more knowledge needs to be cultivated to understand the relationship between polymer characteristics and particle formation. Since characteristics of Pluronic micellar assemblies can be easily modified by varying the copolymer concentration and temperature, tuning up the shape and size of the overall morphology of NPs and in consequence their optical, electronic, and catalytic properties is possible $[15,16]$. These findings raised our interest in the widely used Pluronic P103 since under our understanding its phase diagram has not been exploited in the synthesis of Ag-NPs.

The aim of this work was to analyse the effect of Pluronic P103 concentration as well as synthesis temperature during Ag-NP formation on their kinetics, size, and morphology. The methodology presented here takes full advantage of the micellar structures and structural changes of Pluronic P103, exploring the properties that allow the copolymer to function as stabilizer and/or nanoreactor. Nanoparticle nucleation and growth were monitored by UV-Vis spectroscopy while their morphology (size and shape) was investigated by TEM. The scattering intensity and the hydrodynamic diameter as well as size distributions of the particles were measured using DLS. These parameters altogether were used to obtain insights into the relationship between the resulting structure of micelles of Pluronic P103 and the size and shape of formed $\mathrm{Ag}$-NPs as a function of synthesis temperature and copolymer concentration.

\section{Materials and Methods}

2.1. Reagents. Silver nitrate $\left(\mathrm{AgNO}_{3}, 99.99 \%\right)$ and sodium borohydride $\left(\mathrm{NaBH}_{4}, 99.8 \%\right)$ were obtained from SigmaAldrich. Pluronic P103 ((PEO) $\left.)_{17}(\mathrm{PPO})_{60}-(\mathrm{PEO})_{17}\right)$ supplied by BASF was used without further purification. All solutions were prepared with triple distilled water.
2.2. Synthesis of Hybrid Silver/P103 Nanoparticles. Aqueous P103 solutions corresponding to concentrations below and above CMC (0.01 wt \% and $1 \mathrm{wt} \%)$ were prepared. After this first step, the solutions were kept in water baths at different temperatures $\left(25,30,35\right.$, and $\left.40^{\circ} \mathrm{C}\right)$ for another $12 \mathrm{~h}$ to ensure Pluronic P103 stabilization. Fresh $\mathrm{NaBH}_{4}(7 \mathrm{mM})$ and $\mathrm{AgNO}_{3}(1 \mathrm{mM})$ concentrated solutions were prepared using distilled water.

Reduction of silver ions was achieved when $\mathrm{AgNO}_{3}$ was added to a solution containing $\mathrm{NaBH}_{4}$ and Pluronic P103. Final molar proportion was $1: 4: 4$ for $\mathrm{AgNO}_{3}$ :P103:$\mathrm{NaBH}_{4}$, respectively.

2.3. Characterization. Optical properties of silver colloidal solutions were studied and analysed by UV-Vis spectroscopy using a GENESYS 10S UV-visible spectrophotometer (Thermo Scientific) at $25^{\circ} \mathrm{C}$ and quartz cells with optical path of $1 \mathrm{~cm}$.

Size and shape of Ag-NPs were determined by TEM analyses, using a JEOL-JEM-2010 in conventional transmission mode, operating at $80 \mathrm{kV}$. For this characterization, samples were prepared by placing a drop of the solution on a carbon-coated $\mathrm{Cu}$ grid before air drying them. This analysis was carried out on solutions that exhibited a constant plasmon resonance band.

DLS analysis was performed using a Malvern Zetasizer 4000 instrument. The light source was a $5 \mathrm{~mW} \mathrm{He-Ne}$ laser, operating at $632.8 \mathrm{~nm}$. Scattering angle was kept at $90^{\circ}$. Measuring time was fixed to 30 seconds with sets of 5 measurements.

\section{Results and Discussion}

3.1. UV-Vis Absorption. Figure 1(a) shows the UV-Vis absorption spectra for Ag-NPs obtained during the reduction of $\mathrm{AgNO}_{3}$ plus $\mathrm{NaBH}_{4}$ in the absence of Pluronic P103 at $25^{\circ} \mathrm{C}$ throughout time. Colloidal solutions without polymer exhibit a fast increase in absorption intensity at early stages of reaction time $(1 \mathrm{~min})$, where maximum plasmon resonance absorbance $\left(I_{\max }\right)$ is ca. 3.4 a.u. Notice a relatively narrow plasmon band centered at the maximum wavelength $\left(\lambda_{\max }\right)$ of ca. $382 \mathrm{~nm}$, denoting the formation of Ag-NPs [13]. However, when reaction time exceeds 30 minutes, the plasmon band changes with time, i.e., a decrease of $I_{\max }$ (associated with a redshift from $382 \mathrm{~nm}$ to $408 \mathrm{~nm}$ ) and a band broadening occurring simultaneously. It has been reported that an increment of peak area of the band indicates a decrease of interparticle spacing, which evidences particle aggregation [17].

Figure 1(b) shows UV-Vis absorption spectra of $\mathrm{AgNO}_{3}$ colloidal solutions prepared with $0.01 \mathrm{wt} \% \mathrm{P} 103$ at $25^{\circ} \mathrm{C}$. At this concentration, monomers of Pluronic P103 are formed [18]. A gradual increase of absorption intensity is observed at the early stages of reaction time ( 1 to 40 minutes). This behavior suggests a slow growth of Ag-NPs, which is related to a simultaneous increase of NPs in number and/or in size [14]. In addition, a band at $\lambda_{\max }$ of ca. $386 \mathrm{~nm}$ with an $I_{\max }$ of ca. 1.7 a.u. shows up. Nevertheless, a decrease in $I_{\max }$ and a redshift in the emission peak at longer time is observed. 


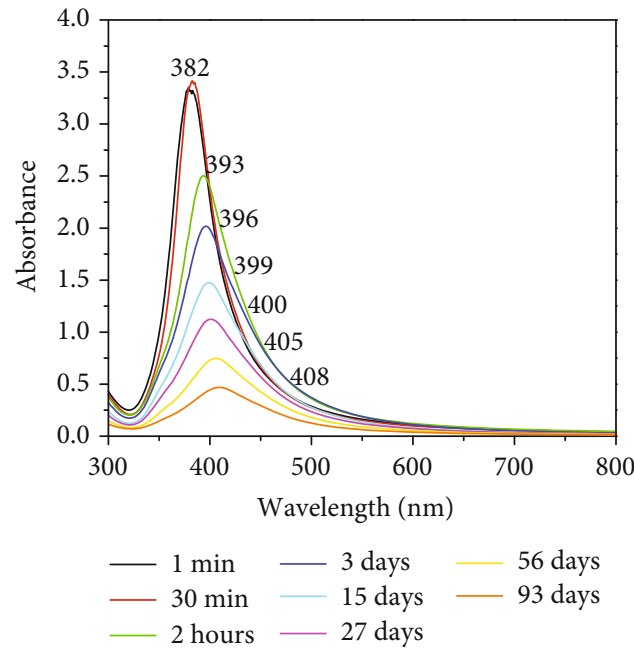

(a)

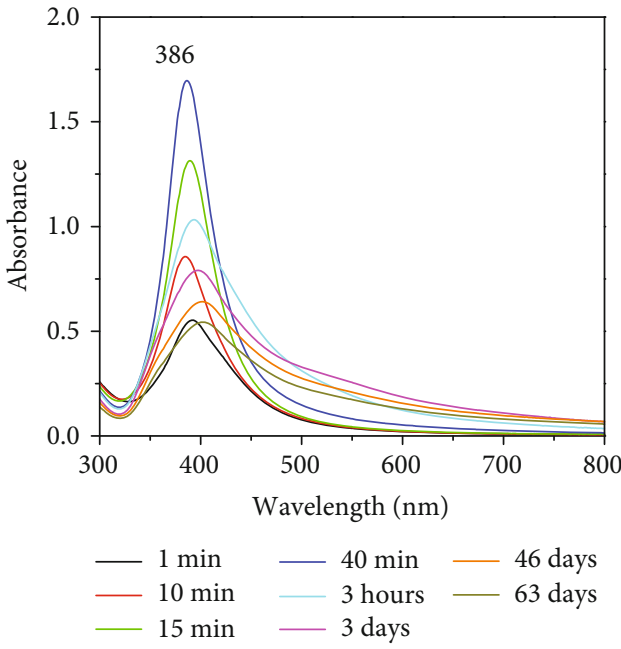

(b)

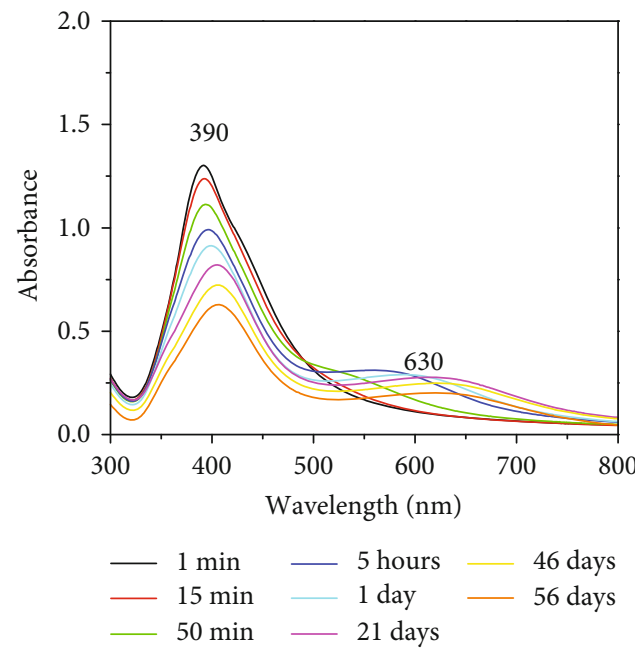

(c)

Figure 1: Surface plasmon resonance absorption spectra of Ag-NPs synthesized at $25^{\circ} \mathrm{C}$ : (a) in the absence of Pluronic P103; (b) with 0.01 wt $\%$ of P103; (c) with 1 wt\% of P103.

The redshift of the peak may be associated with an increase in particle size and/or surface alteration due to the polymer [14].

Figure 1(c) shows UV-Vis absorption spectra for a sample prepared with $1 \mathrm{wt} \% \mathrm{P} 103$ at $25^{\circ} \mathrm{C}$. At this concentration, a combination of Pluronic P103 monomers and micelles is formed [18]. Notice how the maximum absorbance $\left(I_{\max }\right.$ of ca. 1.3 a.u. with $\lambda_{\max }$ at ca. $390 \mathrm{~nm}$ ) is reached at very short times exhibiting wide absorption bands. After 50 minutes, the absorption band becomes narrower. Notably, in the long run, the plasmon band develops a second shallow maximum at ca. $630 \mathrm{~nm}$. This behavior suggests that the increase in polymer concentration promotes formation of spherical and anisotropic structures $[19,20]$.

The corresponding kinetic of Ag-NP growth as a function of Pluronic P103 concentration at $25^{\circ} \mathrm{C}$ is shown in Figure 2, in terms of $I_{\max }$ (Figure 2(a)) and $\lambda_{\max }$ (Figure 2(b)) over time. The behavior observed in both polymer-free and polymer-containing solutions is very different between them. For the polymer-free colloidal solution, an immediate increase in $I_{\max }$ at ca. 3.4 a.u. occurs (Figure 2(a)) remaining constant for 30 minutes. This suggests that formation of Ag-NPs was immediate due to the reducing agent. It is already known that the magnitude of the intensity depends on the density of NPs dispersed in the solution [21]. Simultaneously, a nearly constant $\lambda_{\max }$ for approximately $10 \mathrm{~min}$ is observed (Figure 2(b)), which may be attributed to an increase in the number of Ag-NPs [21]. When reaction time exceeds $50 \mathrm{~min}$, a drastic decrease in $I_{\max }$ is observed followed by a $\lambda_{\max }$ redshift of ca. $25 \mathrm{~nm}$. These changes can be attributed to the significant augmentation of size or self-aggregation of the Ag-NPs [10]. When Pluronic P103 is used below the CMC (0.01 wt\%), $I_{\max }$ increases linearly during the first $10 \mathrm{~min}$, whereas, from 10 to 50 minutes, the increment is exponential. This suggests that the nucleation process is carried out in two stages: a slow 


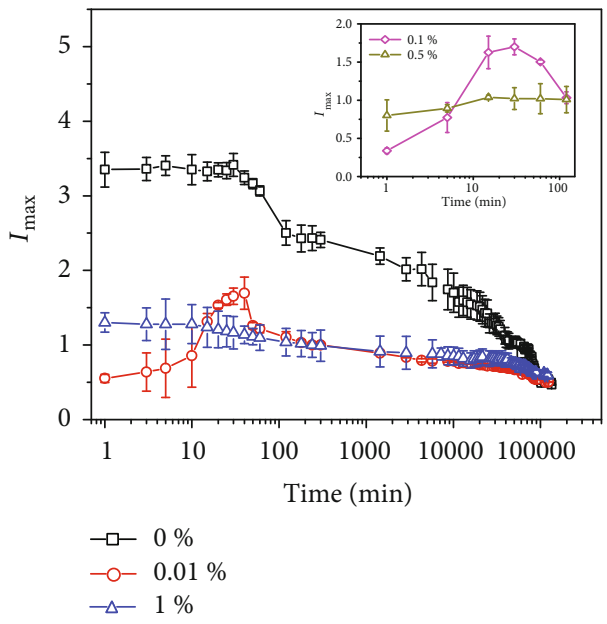

(a)

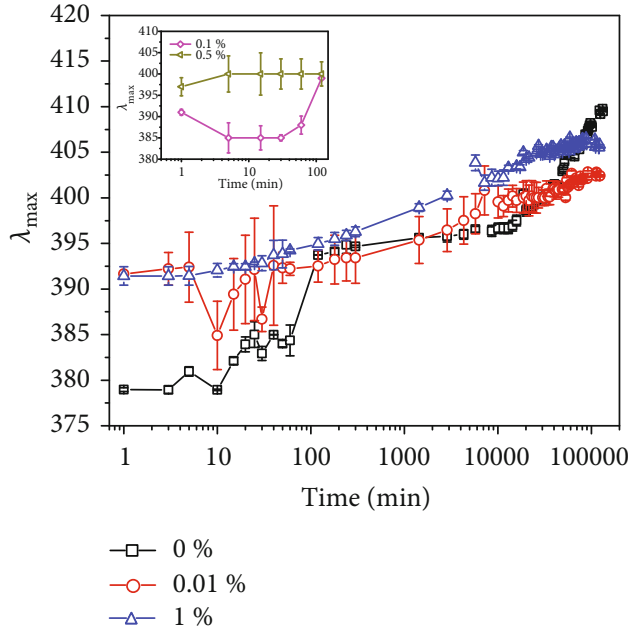

(b)

Figure 2: Semilog plot of (a) $I_{\max }$ and (b) $\lambda_{\max }$ as a function of reaction time for Ag-NPs synthesized at $25^{\circ} \mathrm{C}$ and different Pluronic P103 concentrations $(\mathrm{wt} \%):(\square) 0 ;(O) 0.01 ;(\triangle) 1$. Solid lines are aides to the eye. Inset in both graphs corresponds to concentrations of 0.1 and $0.5 \mathrm{wt} \%$. Error bars indicate standard deviation for triplicate measurements.

process and a fast one. During the first-stage, the presence of monomers of the triblock copolymer together with $\mathrm{NaBH}_{4}$ promotes the continuous formation of Ag-NPs (slow process). However, in the second stage, it is possible that Pluronic $\mathrm{P} 103$ monomers start to run out, causing the remaining ions to interact exclusively with $\mathrm{NaBH}_{4}$ due to the polymer shortage, forming Ag-NPs at a faster rate. After 60 minutes, $I_{\max }$ decreases with a redshift of $\lambda_{\max }$ of ca. $11 \mathrm{~nm}$ indicating a further increment of size of the particles. On the other hand, when Pluronic P103 is used above its CMC (1 wt\%), $I_{\max }$ is constant during the first 10 minutes of reaction. This suggests that Pluronic P103 micelles affect the synthesis kinetics of NPs. In addition, $\lambda_{\max }$ shows a redshift at longer times from which similar conclusions as with the former concentration can be obtained.

To observe the effect of the polymer at intermediate concentrations on the synthesis of Ag-NPs, some experiments were conducted with Pluronic P103 at 0.1 and $0.5 \mathrm{wt} \%$. In the inset of Figure 2(a), it is shown that $I_{\max }$ for solutions of 0.1 and $0.5 \mathrm{wt} \%$ of Pluronic P103 behaves in a similar way to the solutions prepared at 0.01 and $1 \mathrm{wt} \%$ of Pluronic P103, respectively. It is evident that the increase in polymer concentration, which in turn increases the presence of micelles, modifies the kinetics, particularly at the beginning of the reaction. Similarly, in the inset of Figure 2(b), $\lambda_{\max }$ exhibits a blueshift $[17,22]$ for both concentrations: 0.01 and $0.1 \mathrm{wt} \%$. Shengtai et al. [23] reported that a blueshift describes a process where recently formed large particles decompose into small ones. Later on, the blueshift turned into a redshift since large particles are no longer decomposing. On the other hand, when increasing the concentration to 0.5 or $1 \mathrm{wt} \%$, only a redshift was observed, even at prolonged times. According to these results, the effect that the concentration of Pluronic P103 has on $I_{\max }$ and $\lambda_{\max }$, due to formation of different structures of polymer, is clearly seen.
Figure 3 shows a surface plasmon resonance absorption spectra of Ag-NPs synthesized with $1 \mathrm{wt} \%$ P103 at different temperatures. In Figure $3(\mathrm{a})$, at $30^{\circ} \mathrm{C}, \lambda_{\max }$ is ca. $405 \mathrm{~nm}$ and a redshift from 405 to $418 \mathrm{~nm}$ is observed. However, when temperature is increased to $35^{\circ} \mathrm{C}$ (Figure $3(\mathrm{~b})$ ), a considerable redshift from 400 to $450 \mathrm{~nm}$ was registered. Additionally, another plasmon band at $\lambda>600 \mathrm{~nm}$ is developed suggesting the selfaggregation of large Ag-NP structures [24]. At $40^{\circ} \mathrm{C}$ (Figure 3(c)), the spectrum shows only one wide absorbance band that exhibits a redshift in function of time from 389 to $423 \mathrm{~nm}$. On the other hand, at $70^{\circ} \mathrm{C}$ where the CPT is reached and phase separation occurs [18], a slight band that disappears after 20 minutes is observed, indicating that NPs were not formed (Figure 3(d)). According to the Pluronic P103 phase diagram reported by Álvarez-Ramírez et al. [18], a rise in temperature starting at $30^{\circ} \mathrm{C}$ increases the size of the micelles leading to the formation of polymer-like micelles. These kinds of micellar structures act as soft templates or nanoreactors where formation of NPs takes place [25]. These results indicate that shape and size of Pluronic P103 micelles modify NP structures, as it will be further corroborated by TEM images.

The corresponding kinetics at temperatures below the $\mathrm{CPT}\left(30,35\right.$, and $\left.40^{\circ} \mathrm{C}\right)$ are shown in Figures 3(e) and 3(f). $I_{\max }$ behavior is different at $30^{\circ} \mathrm{C}$ with respect to 35 and $40^{\circ} \mathrm{C}$, especially at early stages of the reaction (Figure $3(\mathrm{e})$ ). This could be related to structural changes of Pluronic P103 as well as the way in which the polymer interacts with the ions. At 35 and $40^{\circ} \mathrm{C}$, the surface cavities of micelles are available for Ag-NP formation [18]. On the other hand, $\lambda_{\max }$ behavior in Figure 3(f) is different for the three different temperatures. A blueshift was observed only at $35^{\circ} \mathrm{C}$. Elsewhere, a similar initial blueshift has been reported, when reaction rates are slow [14]. It may be noted that at $40^{\circ} \mathrm{C}$, the dynamics 

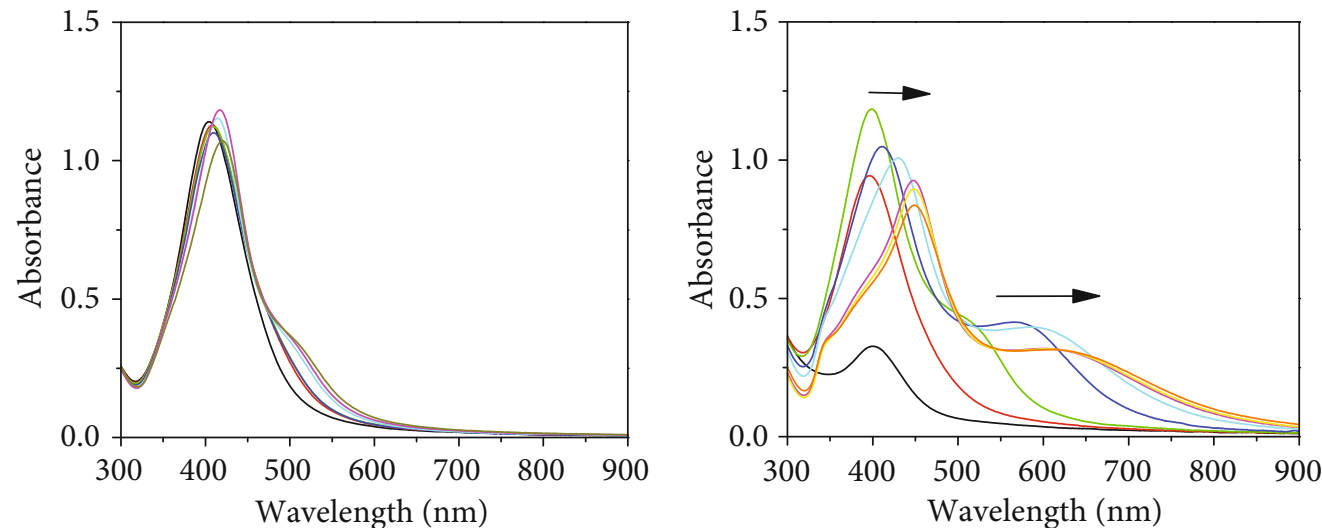

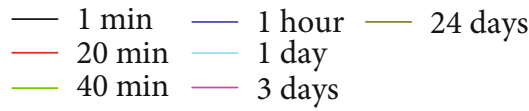

(a)
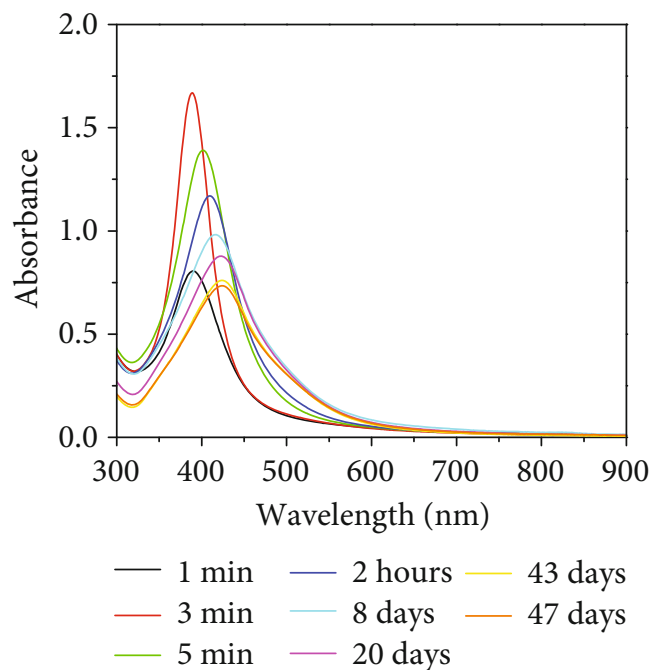

(c)

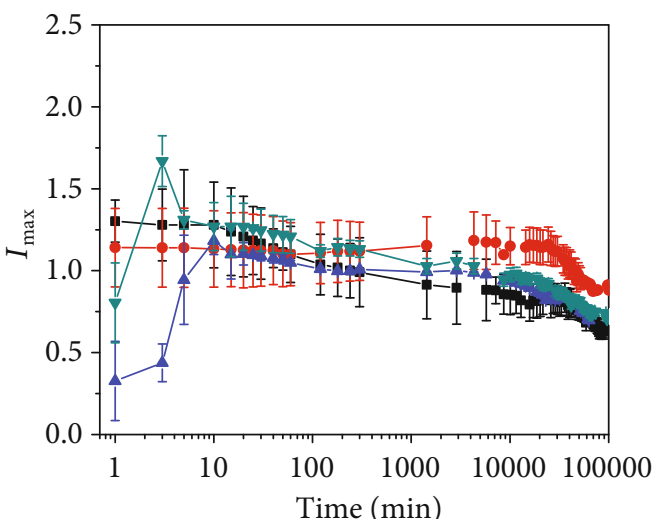

$-25^{\circ} \mathrm{C}$

$-\nabla-40^{\circ} \mathrm{C}$

$-\bullet-30^{\circ} \mathrm{C}$

$-\triangle-35^{\circ} \mathrm{C}$

(e)

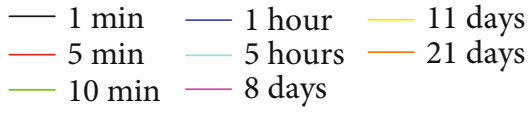

(b)
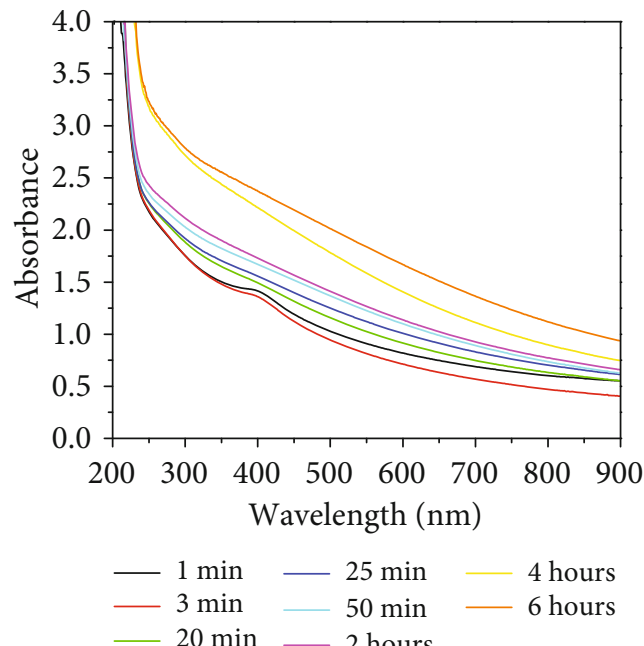

(d)

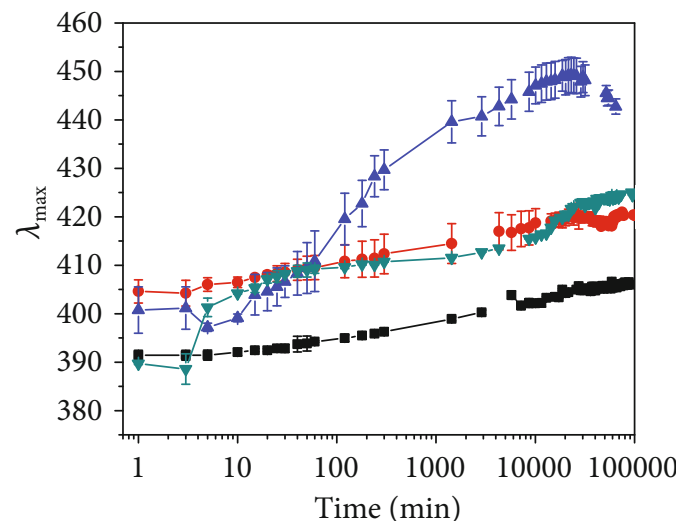

$-25^{\circ} \mathrm{C} \quad-\nabla-40^{\circ} \mathrm{C}$

$-\bullet-30^{\circ} \mathrm{C}$

$-\Delta-35^{\circ} \mathrm{C}$

(f)

FIGURE 3: Surface plasmon resonance absorption spectra of Ag-NPs synthesized with $1 \mathrm{wt} \%$ Pluronic P103 at different temperatures ( $\left.{ }^{\circ} \mathrm{C}\right)$ : (a) 30; (b) 35; (c) 40; (d) 70. Semilog plot of (e) $I_{\max }$ and (f) $\lambda_{\max }$ as function of reaction time for Ag-NPs and different Pluronic P103 temperatures $\left({ }^{\circ} \mathrm{C}\right):(\square) 30 ;(\bigcirc) 35 ;(\triangle)$ 40. Solid lines are aides to the eye. Error bars indicate standard deviation for triplicate measurements. 


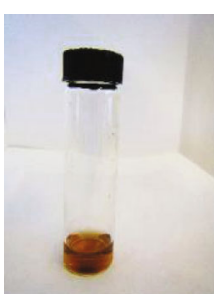

(a)

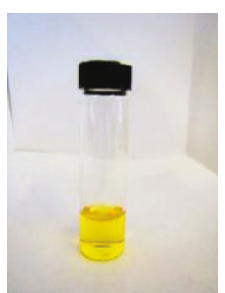

(b)

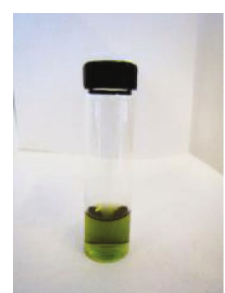

(c)

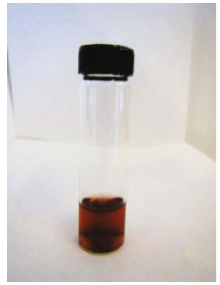

(d)

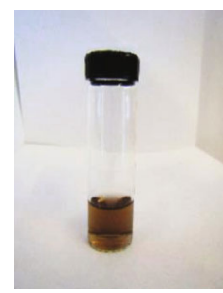

(e)

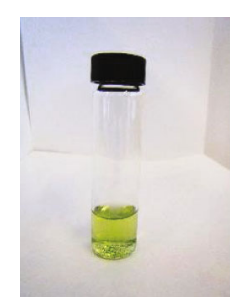

(f)

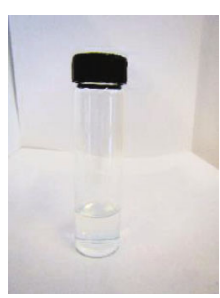

(g)

Figure 4: Photographs of Ag-NP solutions after 3 hours of reaction at different P103 concentrations (wt\%) at 25 $\mathrm{C}$ : (a) 0, (b) 0.01, and (c) 1.0, and for $1 \mathrm{wt} \%$ Pluronic P103 solution at different synthesis temperatures $\left({ }^{\circ} \mathrm{C}\right)$ : (a) 30, (b) 35, (c) 40, and (d) 70.

of the NP formation is relatively fast (within 3 to $10 \mathrm{~min}$ ); thus, the reduction of silver ions is likely to occur within well-formed cavities from the beginning.

Photographs of colloidal solutions after 3 hours of reaction for different concentrations and temperatures are shown in Figure 4. Rows 1 and 2 show photographs of the solutions as a function of Pluronic P103 concentration (0, 0.01, and $1 \mathrm{wt} \%)$ at $25^{\circ} \mathrm{C}$, and synthesis temperature $(30,35,40$, and $70^{\circ} \mathrm{C}$ ) for $1 \mathrm{wt} \%$. Figures $4(\mathrm{a})-4(\mathrm{c})$ show that the color of the solutions changed from brown to green passing for pale yellow, indicating the reduction of $\mathrm{Ag}(1+)$ to $\mathrm{Ag}(0)$. Moreover, notice that color of the Ag-NP solution changed from dark brown at $30^{\circ} \mathrm{C}$ (Figure $4(\mathrm{~d})$ ) to clear brown at $35^{\circ} \mathrm{C}$ (Figure $4(\mathrm{e})$ ), whereas at $40^{\circ} \mathrm{C}$, the color is green (Figure 4(f)). However, when increasing the synthesis temperature to $70^{\circ} \mathrm{C}$, a changed in color is not registered (Figure 4(g)), since Ag-NPs were not formed. The color of the solution is indicative of the reduction of silver ions [26].

3.2. Transmission Electron Microscopy. TEM analysis was used to compare the shape and size of Ag-NPs prepared with and without Pluronic P103 at $25^{\circ} \mathrm{C}$. Figures 5(a) and 5(b) show TEM micrographs of Ag-NPs synthesized without Pluronic P103. A vast quantity of small particles with diameters of $2-5 \mathrm{~nm}$ is observed. Although, some large size particles (20 to $30 \mathrm{~nm}$ ) appear as well. Quasispherical and oval-shaped particles are found. Figure 5(c) shows the particle size distribution histogram where mostly small particles with a mean diameter of $3.6 \mathrm{~nm}$ were identified, with a standard deviation of $3.7 \mathrm{~nm}$. In this context, in the absence of Pluronic P103, $\mathrm{NaBH}_{4}$ acts as a reducer agent generating a large amount of small NPs. However, as the reaction proceeds, these NPs self-aggregate as shown by the UV-Vis spectrum (Figure 1(a)) to form larger NPs.

When a concentration of $0.01 \mathrm{wt} \%$ of Pluronic P103 is used for synthesis (Figures 5(d)-5(f)), spherical-shaped particles are predominantly found with a mean diameter of $9 \mathrm{~nm}$ and a standard deviation of $4 \mathrm{~nm}$. Below CMT, most of the
Pluronic P103 is in a monomer state, promoting the formation of spherical particles with homogeneous size (Figures 5(d) and 5(e)). Figure 5(f) shows the size distribution histogram for a homogeneous population.

TEM studies of Ag-NPs with 1 wt\% P103 demonstrate the presence of micelles acting as templates, where independent big Ag-NPs are formed. Micelles act as nanoreactors, enabling the formation of NPs with similar size as the templates. The silver particle core appears as a dark contrast (indicated with a dash circle in Figure 5(g)), while the polymer has a lighter contrast (indicated with arrows in the same figure). Moreover, fused NPs that give place to anisotropic structures with sizes of $20 \mathrm{~nm}$ are observed (indicated with arrows in Figure 5(h)). The particle size distribution histogram for these Ag-NPs shows a mean diameter of $12 \mathrm{~nm}$ (Figure 5(i)) with a standard deviation of $6.6 \mathrm{~nm}$.

Figures 6(a) and 6(b) show a TEM micrograph of AgNPs synthesized with $1 \mathrm{wt} \%$ of Pluronic P103 at $30^{\circ} \mathrm{C}$. A well-defined oval-shaped micelle with size of ca. $140 \mathrm{~nm}$ acting as a soft template is observed since it has small NPs incorporated into its crown. The mean diameter of the Ag-NPs generated into the micelles is $6.2 \mathrm{~nm}$ (Figure 6(c)) with a standard deviation of $3.2 \mathrm{~nm}$. Since Ag-NPs are arranged on the surface of micelles, hybrid silver/P103 nanomaterials are formed.

If temperature is increased to $35^{\circ} \mathrm{C}$, there is a transition from spherical to polymer-like micelles [18]. Ag-NPs of different sizes (from 2 to $57 \mathrm{~nm}$ ) are observed in Figures 6(d) and $6(\mathrm{e})$. Average size of the nanostructures generated within the micellar template is $5.2 \mathrm{~nm}$ (Figure 6(f)) with a standard deviation of $5.8 \mathrm{~nm}$. Raising the temperature to $35^{\circ} \mathrm{C}$ produced different morphologies, such as spherical, rectangular, and ellipsoidal structures (Figure 6(e)), most probably due to the transition to polymer-like micelles. Accordingly, the asymmetric nature of the band showed in the UV-Vis absorption spectrum in Figure 3(b) can be attributed to the anisotropic nature of the synthesized material. 


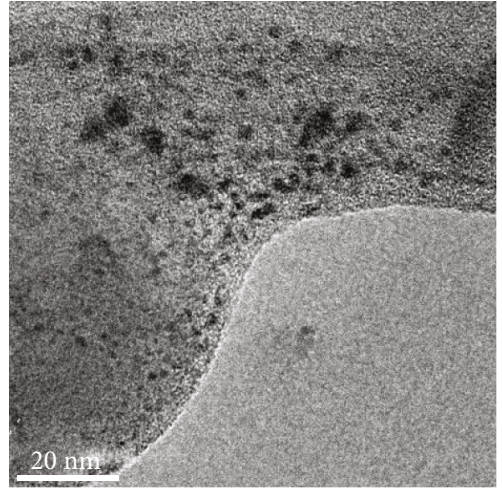

(a)

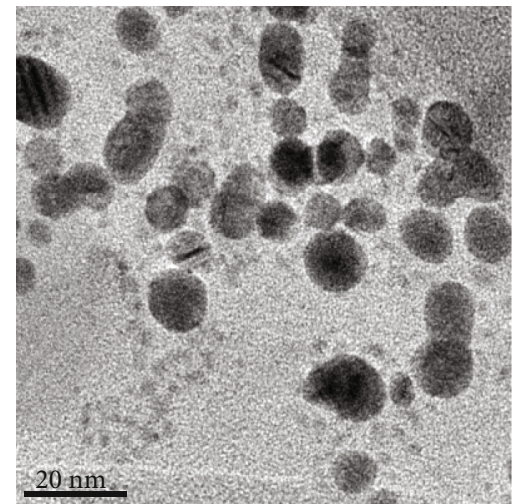

(d)

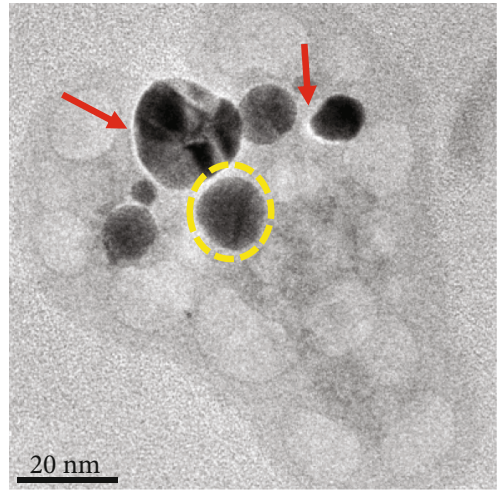

(g)

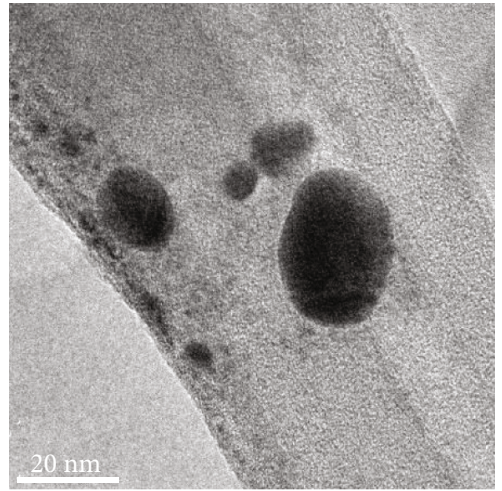

(b)

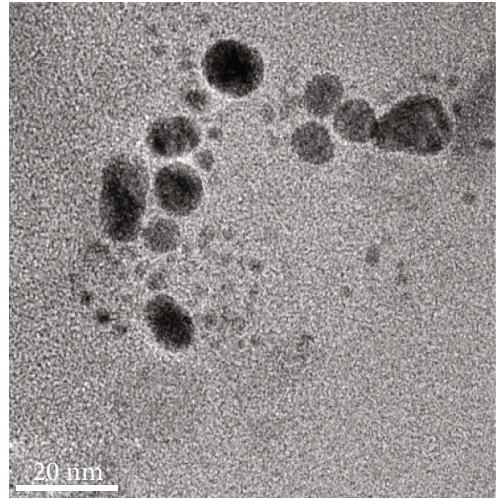

(e)

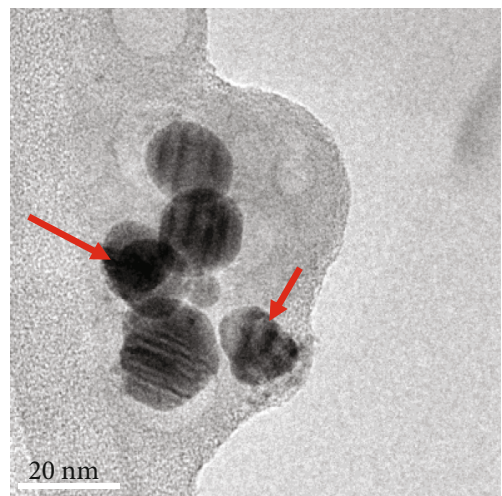

(h)

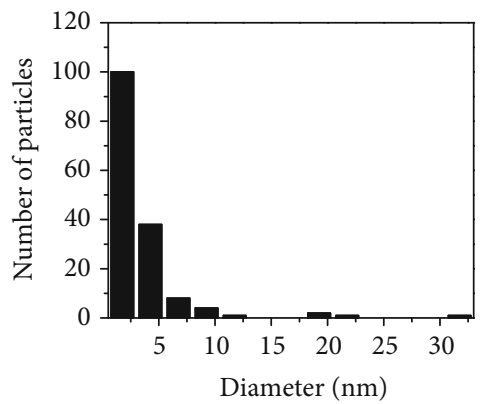

(c)

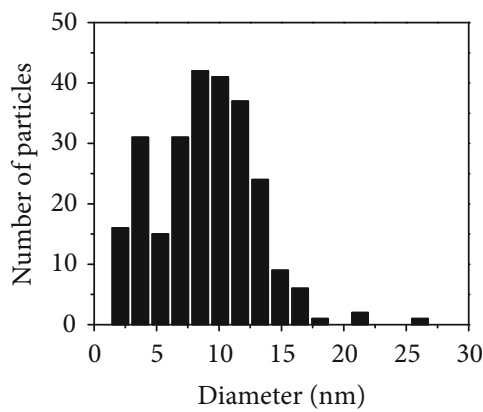

(f)

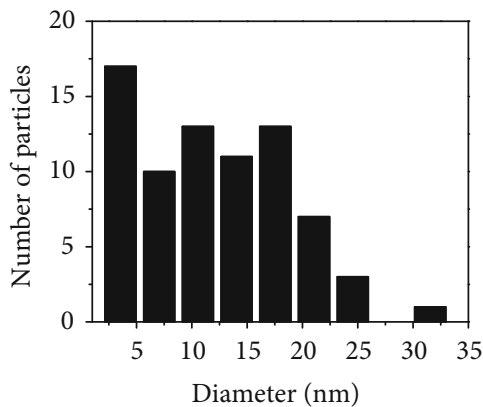

(i)

FIgure 5: TEM micrographs of Ag-NPs synthesized at $25^{\circ} \mathrm{C}$. (a) and (b) show Ag-NPs synthesized without Pluronic P103 while (c) shows the particle size distribution histogram. (d) and (e) show Ag-NPs synthesized with $0.01 \mathrm{wt} \% \mathrm{P} 103$ and (f) the particle size distribution histogram. (g) and (h) show Ag-NPs synthesized with $1 \mathrm{wt} \%$ P103 and (i) the particle size distribution histogram.

A TEM micrograph of polymer-like micelle/Ag-NP assemblies prepared with $1 \mathrm{wt} \% \mathrm{P} 103$ at $40^{\circ} \mathrm{C}$ is shown in Figure 6(g). Notice that polymer-like micelles carry dark Ag-NPs with sizes of ca. $3.8 \mathrm{~nm}$ (Figure 6(h)) on their surfaces with a standard deviation of $1.2 \mathrm{~nm}$. Independent Ag-NPs are not observed, which suggests that tiny Ag-NPs grow on the surface cavities of the micelles, which are acting as templates for self-assembly $[27,28]$. It is well known that an increase in temperature of the triblock copolymer solutions promotes hydrophobicity of polymer-like micelles, compacting them along with their surface cavities $[10,18]$. Thus, compact cavities (centers of nucleation) accept certain number of atoms of $\mathrm{Ag}(0)$ forming tiny Ag-NPs of uniform size. Polymer-like micelles effectively prevent the aggregation of Ag-NPs, acting as a template to immobilize them, improving their dispersibility [12].

3.3. Dynamic Light Scattering. In order to efficiently comprehend the structural changes of $\mathrm{Ag}-\mathrm{NPs}$ at $25^{\circ} \mathrm{C}$, their structure with and without Pluronic P103 was investigated using DLS. Figure 7(a) shows the size distributions of Ag-NPs synthesized without Pluronic P103 at short times. The comparison between intensity, volume, and number as a function of particle diameter is shown. Intensity (continuous black line) 


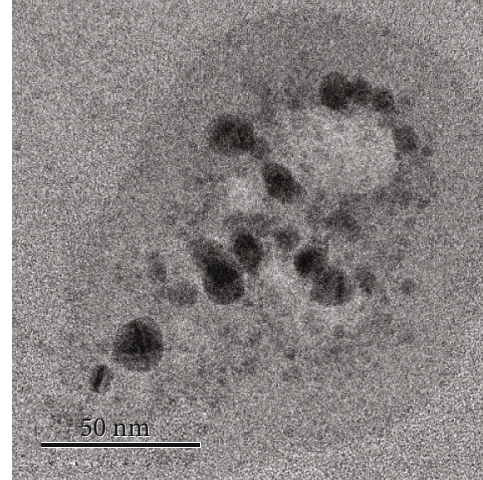

(a)

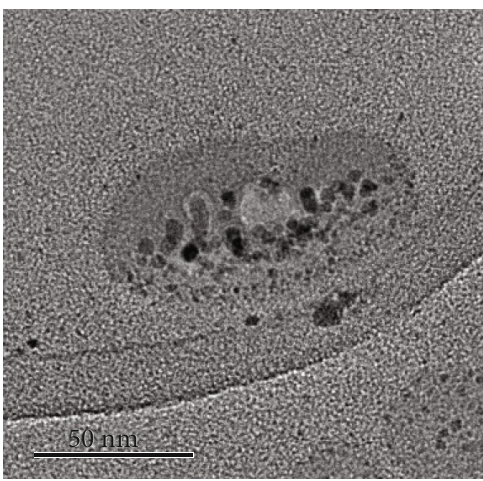

(d)

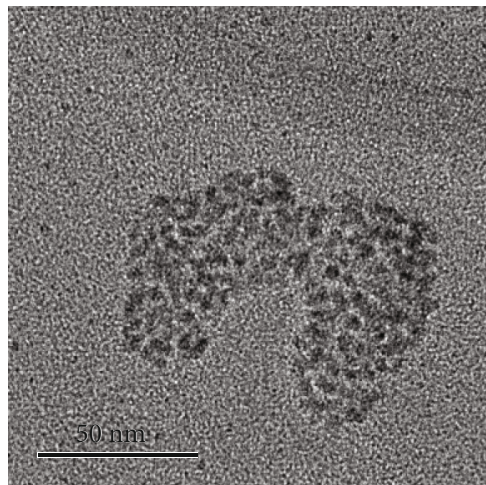

(g)

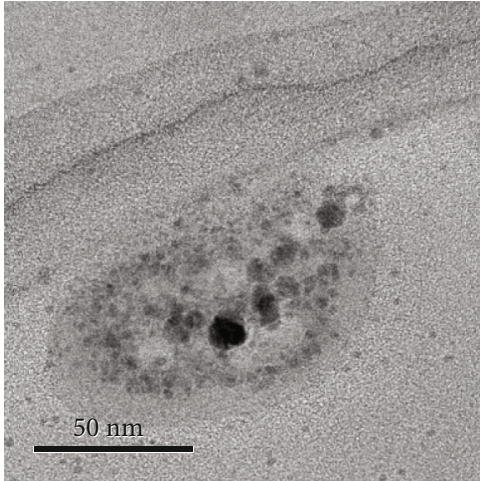

(b)

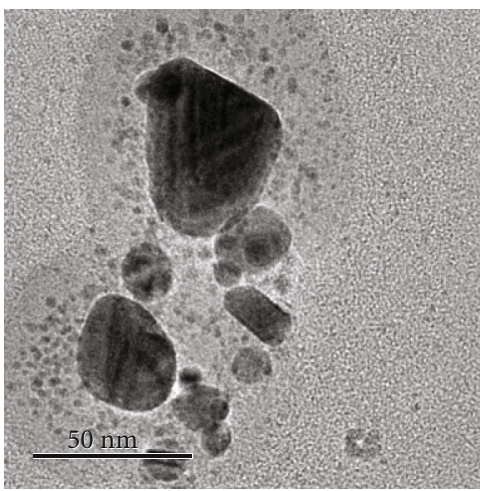

(e)

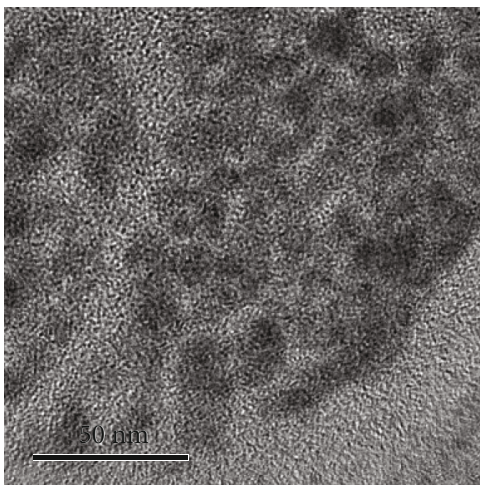

(h)

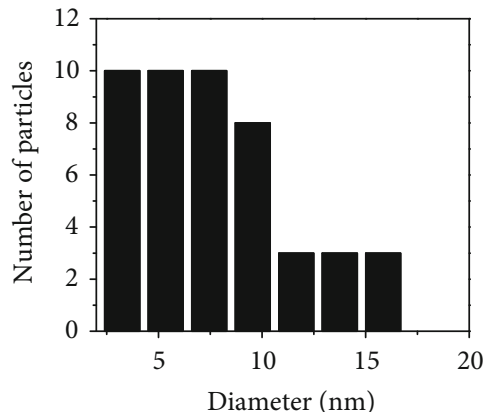

(c)

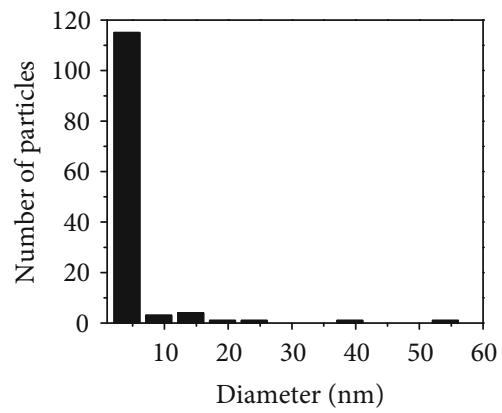

(f)

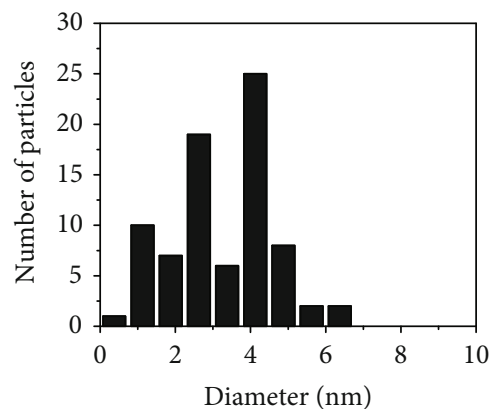

(i)

Figure 6: TEM micrographs of Ag-NPs synthesized with $1 \mathrm{wt} \%$ P103. (a) and (b) show Ag-NPs synthesized at $30^{\circ} \mathrm{C}$ and (c) their particle size distribution histogram. (d) and (e) show Ag-NPs synthesized at $35^{\circ} \mathrm{C}$ and (f) their particle size distribution histogram. Finally, (g) and (h) show Ag-NPs synthesized at $40^{\circ} \mathrm{C}$ and (i) their particle size distribution histogram.

analysis shows a trimodal distribution, where a very small population of tiny Ag-NPs (3.1 nm), a considerable population of small Ag-NPs $(11.7 \mathrm{~nm})$, and a larger population of big Ag-NPs (76.3 nm) are observed. However, the size distributions regarding volume (dashed blue line) and number (dotted red line) show unimodal distributions with high populations of tiny Ag-NPs with average diameters of $2.7 \mathrm{~nm}$ and $2.6 \mathrm{~nm}$, respectively. Therefore, it can be inferred that the amount of small and big Ag-NPs in the colloidal solution without Pluronic P103 is not significant. Other authors have reported a similar behavior [29]. These authors observed multimodal distributions in DLS measurements. They attributed the formation of multiple relaxation times to particle self-diffusion as well as diffusion of aggregates held together via weak interactions. The inset in Figure 7(a) shows the size distribution of Ag-NPs at long times, where particle diameter increases. Size distribution results corroborate the redshift behavior in the UV-Vis spectra (Figure 1(a)). Moreover, the Ag-NP diameters correspond to the size of Ag-NPs observed by TEM micrographs shown in Figures 5(a) and 5(b).

Figure 7(b) shows the size distributions of Ag-NPs synthesized with $0.01 \mathrm{wt} \%$ Pluronic P103 at $25^{\circ} \mathrm{C}$. The intensity distribution (continuous black line) shows a bimodal distribution at short times. Here, Ag-NP diameters range from 7 to $250 \mathrm{~nm}$ with two peaks located at ca. 18 and $120 \mathrm{~nm}$. The first peak is attributed to single NPs and the second peak is 


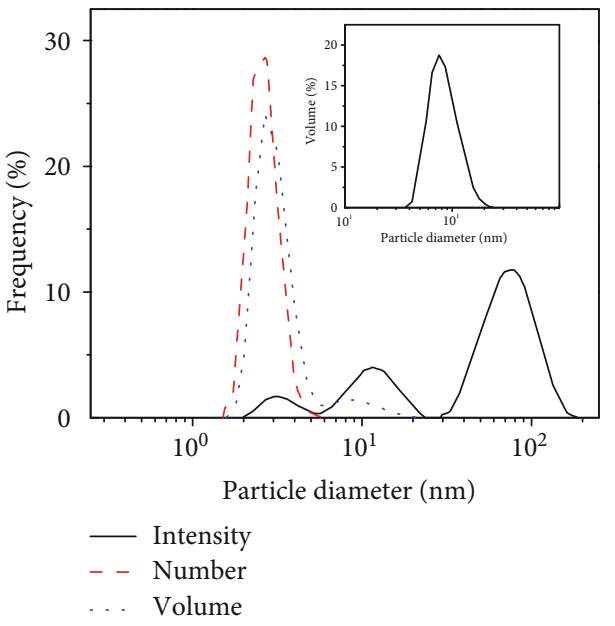

(a)

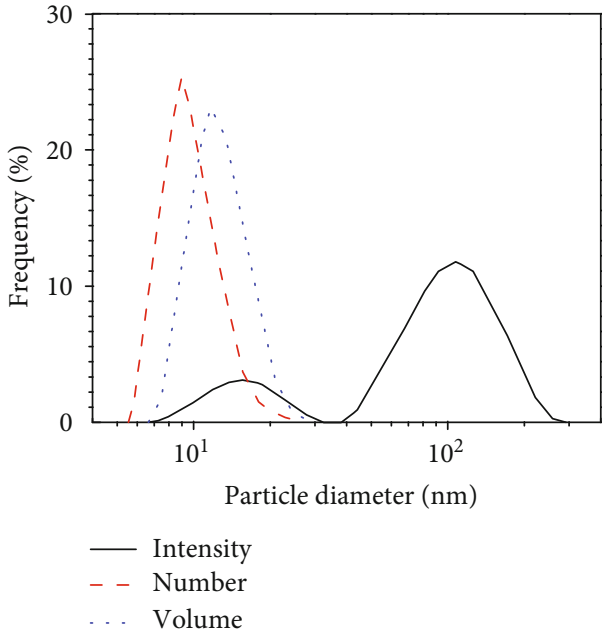

(b)
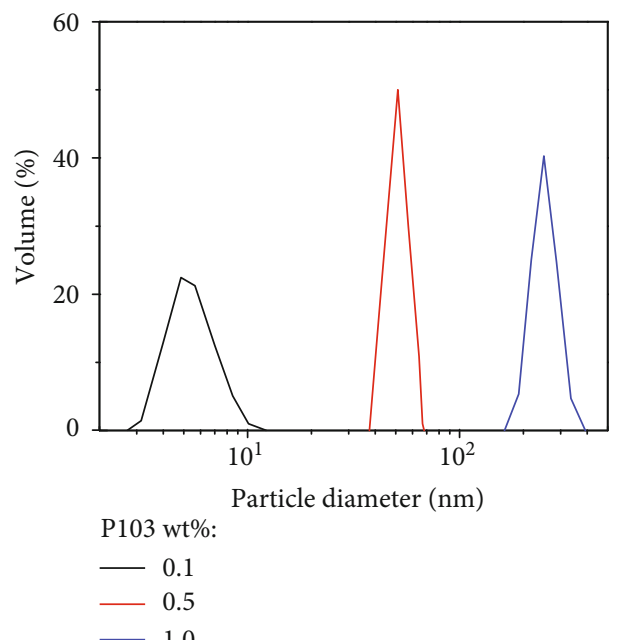

(c)

Figure 7: DLS plots for size distribution profiles of Ag-NPs synthesized at $25^{\circ} \mathrm{C}$ with and without Pluronic P103 at different concentrations (wt\%): comparison of intensity, number, and volume of (a) 0 and (b) $0.01 \mathrm{wt} \%$; (c) particle diameter in volume of Ag-NPs with different concentrations of Pluronic P103.

assigned to aggregates of Ag-NPs. A similar behavior has been reported in the formation of Pluronic F127-gold hybrid NPs [30]. A considerable population around $10 \mathrm{~nm}$ appears in the volume and number distributions. These diameters are similar to the size of Ag-NPs observed by TEM micrographs shown in Figures 5(d) and 5(e).

For Ag-NPs synthesized with $0.1,0.5$, and $1 \mathrm{wt} \%$ of Pluronic P103 (Figure 7(c)), volume analysis shows an increase in size with P103 concentration. When Ag-NPs are synthesized with $1 \mathrm{wt} \%$ Pluronic P103, larger particle diameters are detected which suggests formation of Ag-NP aggregates or the presence of groups of spherical micelles, as observed by TEM analysis (Figure $5(\mathrm{~g})$ ). Nanoparticle sizes determined by DLS are larger compared to the ones determined by TEM. DLS measures both metal particle and polymer micelles [31]. Additionally, the size distributions of the Ag-NPs are listed in Table 1.
TABle 1: Size distribution of Ag-NPs synthesized at different Pluronic P103 concentrations, at $25^{\circ} \mathrm{C}$.

\begin{tabular}{lccc}
\hline $\begin{array}{l}\text { Concentration of } \\
\text { Pluronic P103 (wt\%) }\end{array}$ & $\begin{array}{c}\text { Size }(\mathrm{nm}) \\
\text { (intensity) }\end{array}$ & $\begin{array}{c}\text { Size }(\mathrm{nm}) \\
\text { (number) }\end{array}$ & $\begin{array}{c}\text { Size }(\mathrm{nm}) \\
\text { (volume) }\end{array}$ \\
\hline 0 & $3.1 ; 11.7 ; 76.3$ & 2.7 & 2.6 \\
0.01 & 18,120 & 9 & 11 \\
0.1 & - & - & 5 \\
0.5 & - & - & 51 \\
1 & - & - & 239 \\
\hline
\end{tabular}

3.4. Proposed Hybrid Silver/P103 Assembly Formation. According to the kinetics of Ag-NP formation determined by surface plasmon resonance absorption spectra, pathways of nucleation and growth of Ag-NP assembly formation were proposed for each case studied. 


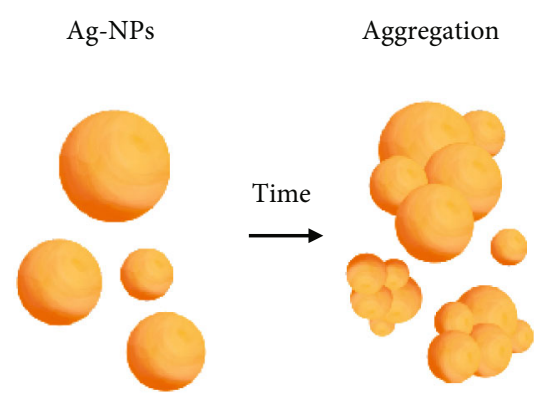

(a)

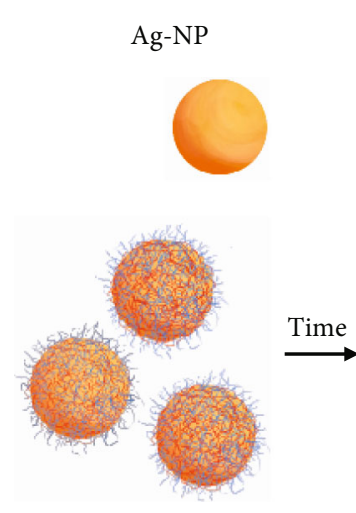

(b)

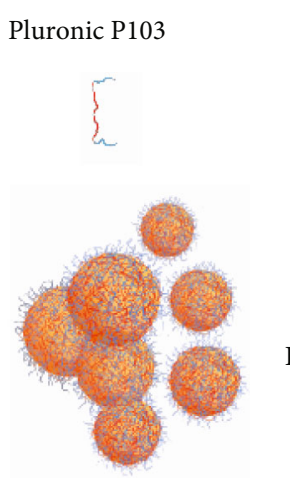

I

II
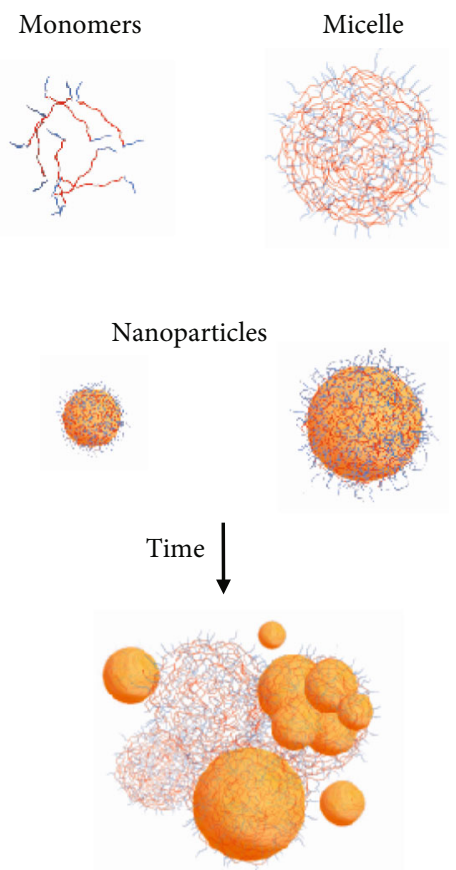

(c)

Figure 8: Scheme of $\mathrm{Ag}(0)$ assemblies at $25^{\circ} \mathrm{C}$ and different concentrations of Pluronic P103 (wt\%): (a) 0, (b) 0.01 , and (c) 1.

In the absence of Pluronic $\mathrm{P} 103$ at $25^{\circ} \mathrm{C}$, when only $\mathrm{NaBH}_{4}$ is present, the nucleation process is immediate due to the excess of reducing agent. This process is followed by uncontrolled growth through time (see scheme in Figure $8(\mathrm{a})$ ). When $0.01 \mathrm{wt} \% \mathrm{P} 103$ is used at $25^{\circ} \mathrm{C}$, polymer monomers are present. Under these circumstances, there is a possibility that both components of the Pluronic P103 may be attached to the NP surface through an adsorption mechanism. As long as the PPO component is anchored, PEO chains are forced to stretch in the solution. As a result, the adsorbed Pluronic P103 adopts a brush-like arrangement (see scheme in Figure 8(b)) $[13,32]$. The monomeric form is not able to participate in the reduction reaction because it cannot generate surface cavities [21]. Finally, these NPs aggregate with time. On the other hand, the presence of the reducer and a large amount of polymer in the micelle form (1 wt\% P103) promote the rapid formation of Ag-NPs (as evidenced by UV-Vis results). At this concentration and $25^{\circ} \mathrm{C}$, monomers plus micelles coexist. In this case, the mechanism of particle formation could take place via two possible ways: (1) at short times, ions with monomers form small nanostructures as previously discussed, while micelles could act as nanoreactors, forming NPs with similar size to these templates, and (2) at long times, some NPs fuse giving rise to anisotropic particles $[19,20]$. This process is shown in the scheme of Figure 8(c).

Pluronic P103 micelles undergo several structure transitions with temperature variations at constant concentration (Figure 9(a)). At $30^{\circ} \mathrm{C}$ where spherical micelles form, they have increased the number of surface cavities that turn into nucleating centers for NP formation. Silver ions interact with surface cavities where they get reduced, initiating the surface redox reaction to produce Ag-NPs. At $35^{\circ} \mathrm{C}$, there is an important change from spherical micelles to polymer-like micelles. This transition promotes an increment in the AgNP size ( $\lambda_{\max }$ shifts to a higher wavelength). However, at $40^{\circ} \mathrm{C}$, the PPO segments of micelles are dehydrated, which lead to formation of cavities with a higher aggregation number and greater surface area; i.e., the reduction process is enhanced (Figure 9(b)). With the increase in temperature, PPO blocks are more exposed to the surrounding environment, favoring its interaction with silver ions and improving the reduction process [19].

\section{Conclusions}

In summary, we present a simple single-step synthesis method of Ag-NPs that uses Pluronic P103 as a stabilizer and/or nanoreactor. It was demonstrated that by means of varying Pluronic P103 concentration and temperature, the synthesis of hybrid silver/P103 nanomaterials with different shapes and sizes is possible. At low Pluronic P103 concentration $(0.01 \mathrm{wt} \%)$ and $25^{\circ} \mathrm{C}$, spherical-shaped Ag-NPs were formed, whereas when increasing Pluronic P103 concentration to $1 \mathrm{wt} \%$, NPs with similar size of the micellar templates were observed. As temperature reached $30^{\circ} \mathrm{C}$, well-defined oval-shaped micelles were formed and small NPs were incorporated into the crown of micelles. However, increasing temperature to $35^{\circ} \mathrm{C}$ resulted in an increment in size of Ag-NPs with spherical and ellipsoidal morphologies, due to the selfassembled micellar Pluronic P103 structure transition from spherical to polymer-like micelles. At $40^{\circ} \mathrm{C}$, it was possible to obtain Ag-NPs with homogeneous size. Monodisperse NPs obtained by soft templates have demonstrated promising behaviors in the catalysis area. Finally, Ag-NPs coated with a physically adsorbed P103 copolymer can subsequently 


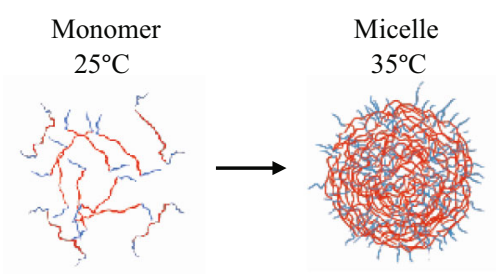

Temperature increase

$35^{\circ} \mathrm{C}$

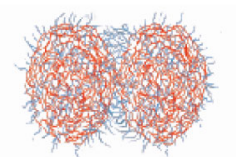

$40^{\circ} \mathrm{C}$

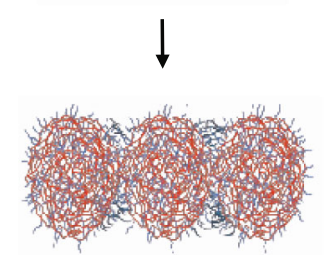

(a)

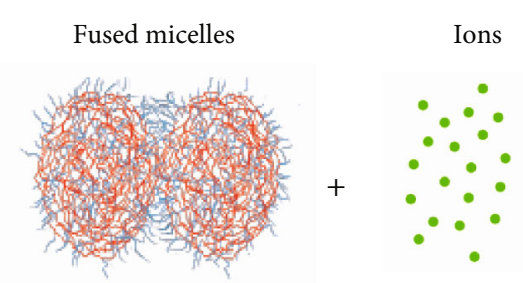

Fused micelles loaded with Ag-NPs

$35^{\circ} \mathrm{C}$

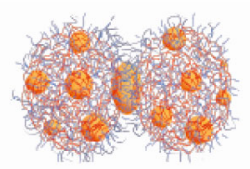

$40^{\circ} \mathrm{C}$

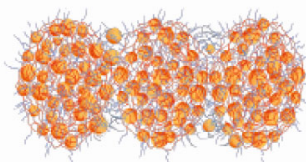

(b)

Figure 9: Scheme of (a) micelle assemblies and (b) synthesis of Ag-NPs using soft templates.

be removed, exchanged, or functionalized with other functional groups; for this reason, these NPs have the potential to be readily integrated into diverse products. Surface-active polymers like Pluronic P103 are very attractive for their commercial availability as well as their biocompatibility; resulting in methodologies with favorable cost and low environmental impact.

\section{Data Availability}

The data used to support the findings of this study are included within the article.

\section{Conflicts of Interest}

The authors declare that there is no conflict of interest regarding the publication of this paper.

\section{Acknowledgments}

The authors are very grateful to Francisco Ruiz and Jaime Mendoza for their technical support with TEM measurements at $\mathrm{CNyN}-\mathrm{UNAM}$. This research was financially supported by Benemérita Universidad Autónoma de Puebla-VIEP 2017-2018.

\section{References}

[1] C. J. Murphy, T. K. Sau, A. M. Gole et al., "Anisotropic metal nanoparticles: synthesis, assembly, and optical applications," The Journal of Physical Chemistry. B, vol. 109, no. 29, pp. 13857-13870, 2005.

[2] X. Hu and S. Liu, "Recent advances towards the fabrication and biomedical applications of responsive polymeric assem- blies and nanoparticle hybrid superstructures," Dalton Transactions, vol. 44, no. 9, pp. 3904-3922, 2015.

[3] A. Gołąbiewska, A. Malankowska, M. Jarek et al., "The effect of gold shape and size on the properties and visible light-induced photoactivity of $\mathrm{Au}-\mathrm{TiO}_{2}$," Applied Catalysis B: Environmental, vol. 196, pp. 27-40, 2016.

[4] B. Liu, T. Jiang, H. Zheng et al., "Nanoengineering of aggregation-free and thermally-stable gold nanoparticles in mesoporous frameworks," Nanoscale, vol. 9, no. 19, pp. 6380-6390, 2017.

[5] Q. H. Tran, V. Q. Nguyen, and A. T. le, "Silver nanoparticles: synthesis, properties, toxicology, applications and perspectives," Advances in Natural Sciences: Nanoscience and Nanotechnology, vol. 4, no. 3, pp. 1-20, 2013.

[6] J. Xu, L. Chen, H. Choi, H. Konish, and X. Li, "Assembly of metals and nanoparticles into novel nanocomposite superstructures," Scientific Reports, vol. 3, no. 1, pp. 1-5, 2013.

[7] L. Kvitek, M. Vanickova, A. Panacek et al., "Initial study on the toxicity of silver nanoparticles (NPs) againstParamecium caudatum," Journal of Physical Chemistry C, vol. 113, no. 11, pp. 4296-4300, 2009.

[8] T. Sakai and P. Alexandridis, "Single-step synthesis and stabilization of metal nanoparticles in aqueous pluronic block copolymer solutions at ambient temperature," Langmuir, vol. 20, no. 20, pp. 8426-8430, 2004.

[9] P. Alexandridis, J. F. Holzwarth, and T. A. Hatton, "Micellization of poly(ethylene oxide)-poly(propylene oxide)-poly(ethylene oxide) triblock copolymers in aqueous solutions: thermodynamics of copolymer association," Macromolecules, vol. 27, no. 9, pp. 2414-2425, 1994.

[10] P. Khullar, A. Mahal, V. Singh, T. S. Banipal, G. Kaur, and M. S. Bakshi, "How PEO-PPO-PEO triblock polymer micelles control the synthesis of gold nanoparticles: temperature and hydrophobic effects," Langmuir, vol. 26, no. 13, pp. 1136311371, 2010. 
[11] T. Sakai, A. Ishihara, and P. Alexandridis, "Block copolymermediated synthesis of silver nanoparticles from silver ions in aqueous media," Colloids and Surfaces A: Physicochemical and Engineering Aspects, vol. 487, pp. 84-91, 2015.

[12] C. Wu, G. Xia, J. Sun, and R. Song, "Synthesis and anisotropic self-assembly of Ag nanoparticles immobilized by the Pluronic F127 triblock copolymer for colorimetric detection of $\mathrm{H}_{2} \mathrm{O}_{2}$," RSC Advances, vol. 5, no. 118, pp. 97648-97657, 2015.

[13] D. G. Angelescu, M. Vasilescu, M. Anastasescu, R. Baratoiu, D. Donescu, and V. S. Teodorescu, "Synthesis and association of $\operatorname{Ag}(0)$ nanoparticles in aqueous Pluronic F127 triblock copolymer solutions," Colloids and Surfaces A: Physicochemical and Engineering Aspects, vol. 394, pp. 57-66, 2012.

[14] A. K. M. M. Islam and M. Mukherjee, "Effect of temperature in synthesis of silver nanoparticles in triblock copolymer micellar solution," Journal of Experimental Nanoscience, vol. 6, no. 6, pp. 596-611, 2011.

[15] M. Aizawa and J. M. Buriak, "Nanoscale patterning of two metals on silicon surfaces using an ABC triblock copolymer template," Journal of the American Chemical Society, vol. 128, no. 17, pp. 5877-5886, 2006.

[16] P. Khullar, V. Singh, A. Mahal et al., "Tuning the shape and size of gold nanoparticles with triblock polymer micelle structure transitions and environments," Journal of Physical Chemistry C, vol. 115, no. 21, pp. 10442-10454, 2011.

[17] R. Desai, V. Mankad, S. K. Gupta, and P. K. Jha, "Size distribution of silver nanoparticles: UV-Visible spectroscopic assessment," Nanoscience and Nanotechnology Letters, vol. 4, no. 1, pp. 30-34, 2012.

[18] J. G. Álvarez-Ramírez, V. V. A. Fernández, E. R. Macías et al., "Phase behavior of the Pluronic P103/water system in the dilute and semi-dilute regimes," Journal of Colloid and Interface Science, vol. 333, no. 2, pp. 655-662, 2009.

[19] P. Alexandridis and M. Tsianou, "Block copolymer-directed metal nanoparticle morphogenesis and organization," European Polymer Journal, vol. 47, no. 4, pp. 569-583, 2011.

[20] D. G. Angelescu, M. Vasilescu, R. Somoghi, D. Donescu, and V.S. Teodorescu, "Kinetics and optical properties of the silver nanoparticles in aqueous L64 block copolymer solutions," Colloids and Surfaces A: Physicochemical and Engineering Aspects, vol. 366, no. 1-3, pp. 155-162, 2010.

[21] M. S. Bakshi, A. Kaura, P. Bhandari, G. Kaur, K. Torigoe, and K. Esumi, "Synthesis of colloidal gold nanoparticles of different morphologies in the presence of triblock polymer micelles," Journal of Nanoscience and Nanotechnology, vol. 6, no. 5, pp. 1405-1410, 2006.

[22] A. V. Perdikaki, P. Tsitoura, E. C. Vermisoglou, N. K. Kanellopoulos, and G. N. Karanikolos, "Poly(ethylene oxide)-b-poly(propylene oxide) amphiphilic block copolymer - mediated growth of silver nanoparticles and their antibacterial behavior," Langmuir, vol. 29, no. 36, pp. 11479-11488, 2013.

[23] S. He, J. Yao, P. Jiang et al., "Formation of silver nanoparticles and self-assembled two-dimensional ordered superlattice," Langmuir, vol. 17, no. 5, pp. 1571-1575, 2001.

[24] A. Slistan-Grijalva, R. Herrera-Urbina, J. F. Rivas-Silva, M. Ávalos-Borja, F. F. Castillón-Barraza, and A. PosadaAmarillas, "Classical theoretical characterization of the surface plasmon absorption band for silver spherical nanoparticles suspended in water and ethylene glycol," Physica E, vol. 27, no. 1-2, pp. 104-112, 2005.
[25] N. Tepale, V. V. A. Fernández-Escamilla, C. Álvarez et al., "Morphological and rheological characterization of gold nanoparticles synthesized using Pluronic P103 as soft template," Journal of Nanomaterials, vol. 2016, Article ID 7494075, 11 pages, 2016.

[26] S. Humbatova, S. Tapdigov, N. Zeynalov, D. Taghiyev, and S. Mammadova, "Synthesis and study of structure silver nanoparticles by polyethyleneglycol - gum Arabic polymers," Journal of Nano Research, vol. 45, pp. 25-33, 2017.

[27] P. Khullar, V. Singh, A. Mahal, H. Kumar, G. Kaur, and M. S. Bakshi, "Block copolymer micelles as nanoreactors for selfassembled morphologies of gold nanoparticles," The Journal of Physical Chemistry. B, vol. 117, no. 10, pp. 3028-3039, 2013.

[28] M. S. Bakshi, "Colloidal micelles of block copolymers as nanoreactors, templates for gold nanoparticles, and vehicles for biomedical applications," Advances in Colloid and Interface Science, vol. 213, pp. 1-20, 2014.

[29] A. Rivas-Cardona, M. Chovanetz, and D. F. Shantz, "A systematic investigation of silicalite-1 precursor mixtures with varying degrees of dilution," Microporous and Mesoporous Materials, vol. 155, pp. 56-64, 2012.

[30] J. D. Antonisamy, J. Swain, and S. Dash, "Study on binding and fluorescence energy transfer efficiency of rhodamine B with Pluronic F127-gold nanohybrid using optical spectroscopy methods," Spectrochimica Acta Part A: Molecular and Biomolecular Spectroscopy, vol. 173, pp. 139-143, 2017.

[31] A. Maciollek and H. Ritter, "One pot synthesis of silver nanoparticles using a cyclodextrin containing polymer as reductant and stabilizer," Beilstein Journal of Nanotechnology, vol. 5, pp. 380-385, 2014.

[32] M. R. Nejadnik, A. L. J. Olsson, P. K. Sharma, H. C. van der Mei, W. Norde, and H. J. Busscher, "Adsorption of Pluronic F-127 on surfaces with different hydrophobicities probed by quartz crystal microbalance with dissipation," Langmuir, vol. 25, no. 11, pp. 6245-6249, 2009. 


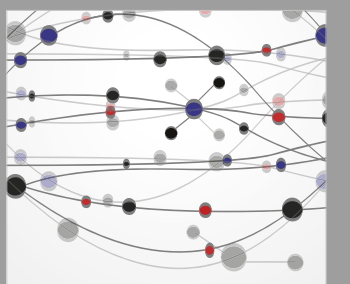

The Scientific World Journal
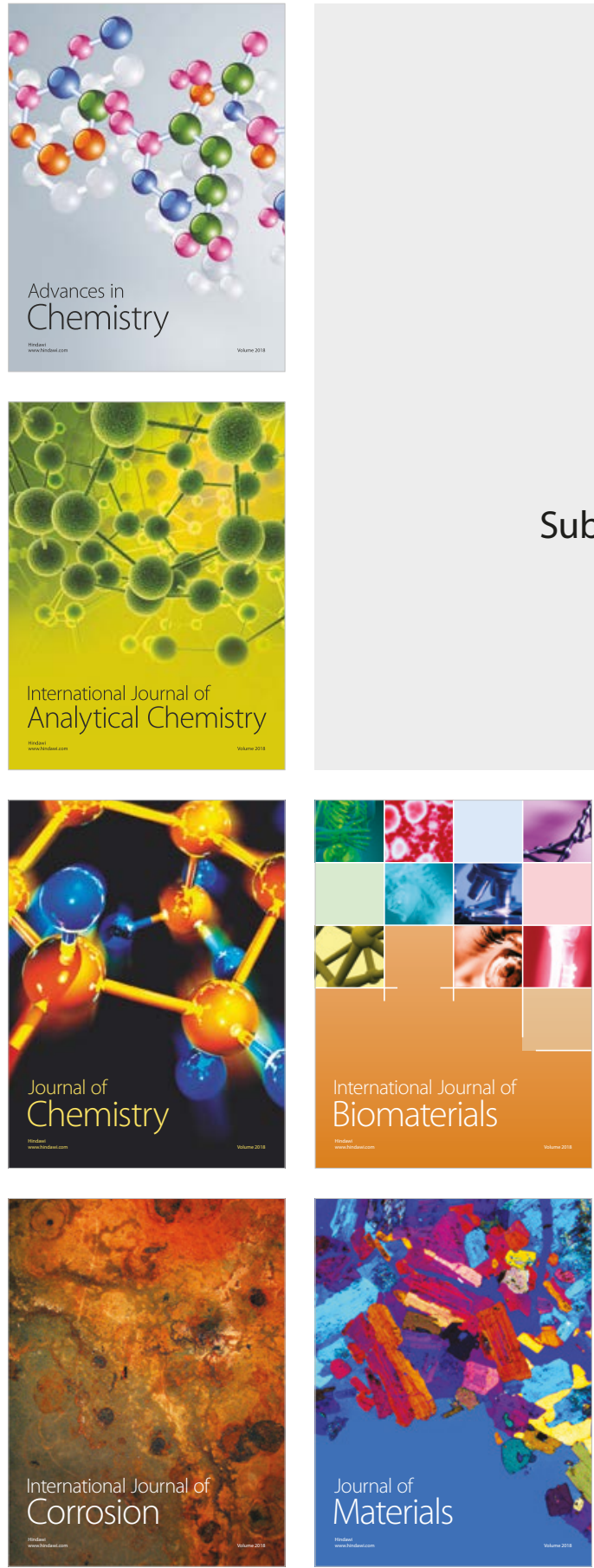

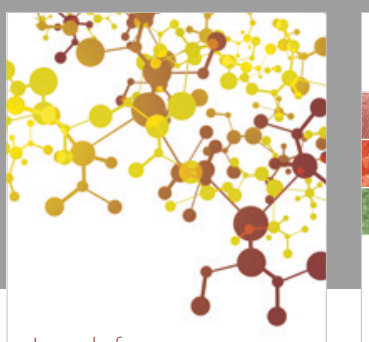

Journal of

Applied Chemistry
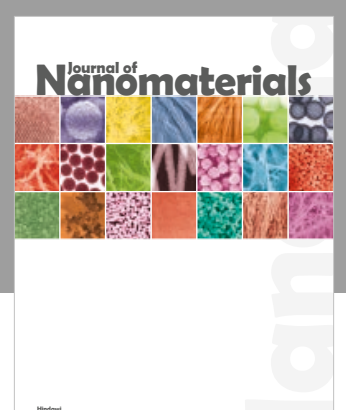

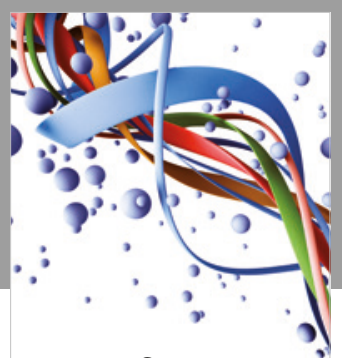

Scientifica

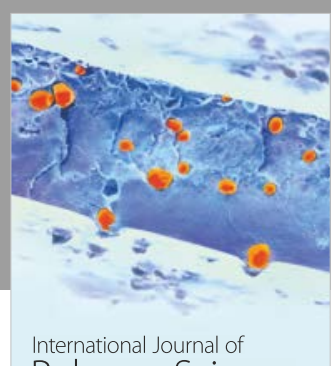

Polymer Science

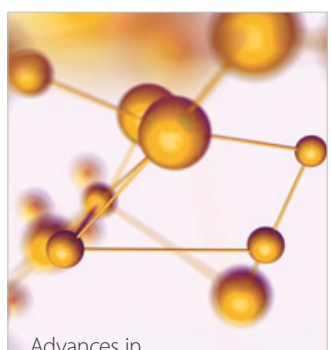

Physical Chemistry
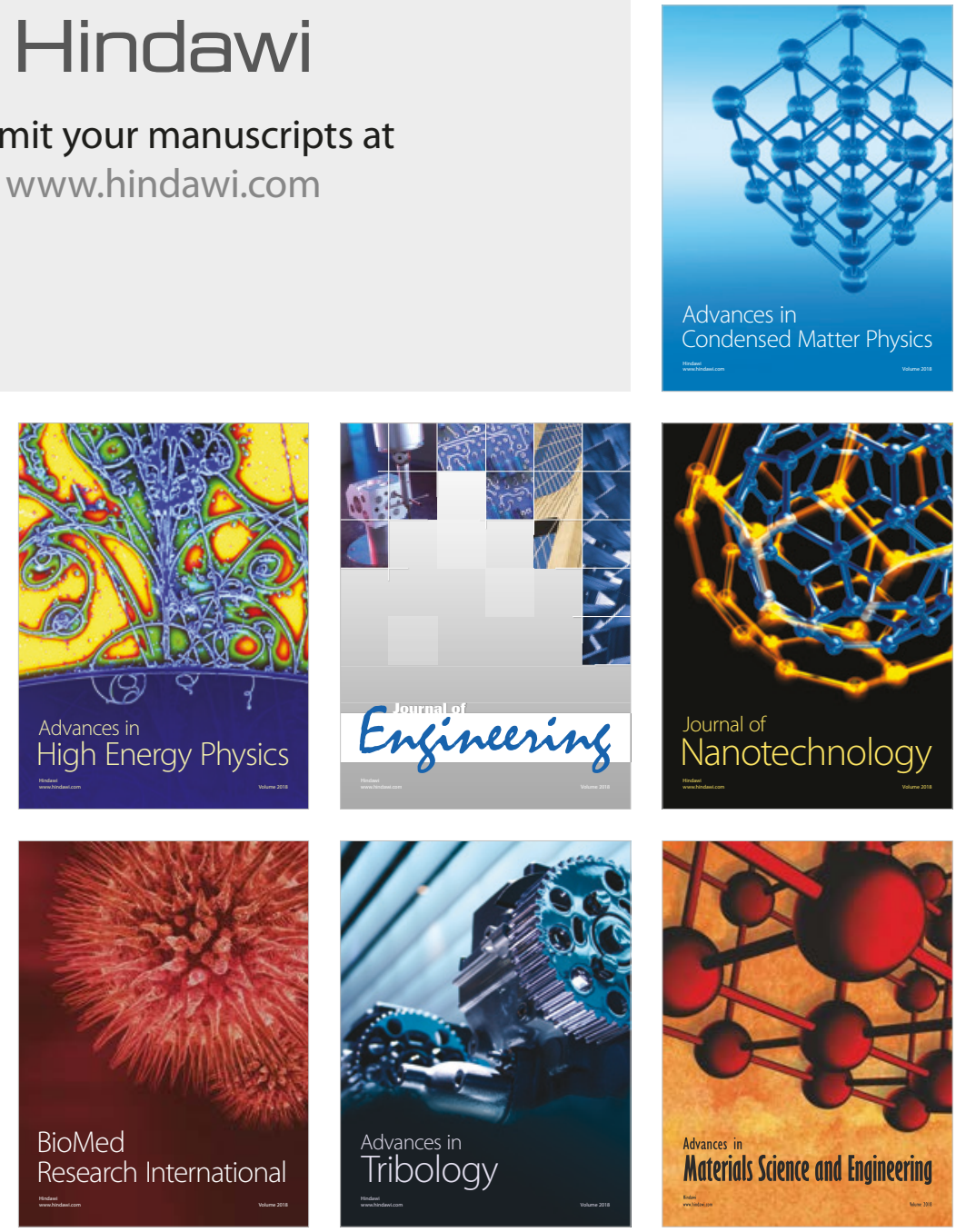